BMJ Open

Sport \&

Exercise

Medicine

\section{Barriers and facilitators to changes in adolescent physical activity during COVID-19}

To cite: $\mathrm{Ng} \mathrm{K}$, Cooper J, McHale $\mathrm{F}$, et al. Barriers and facilitators to changes in adolescent physical activity during COVID-19. BMJ Open Sport \& Exercise Medicine 2020;0: e000919. doi:10.1136/ bmjsem-2020-000919

- Supplemental material is published online only. To view please visit the journal online (http://dx.doi.org/10.1136/ bmjsem-2020-000919).

Accepted 18 0ctober 2020
(C) Author(s) (or their employer(s)) 2020. Re-use permitted under CC BY-NC. No commercial re-use. See rights and permissions. Published by BMJ.

${ }^{1}$ Physical Activity for Health Research Cluster, Health Research Institute, Department of Physical Education and Sport Sciences, University of Limerick, Limerick, Ireland

${ }^{2}$ School of Educational Sciences and Psychology, University of Eastern Finland, Joensuu, Finland

Correspondence to Kwok Ng; Kwok.ng@ul.ie

\section{ABSTRACT}

Objectives COVID-19 restrictions reduced adolescents' opportunities for physical activity (PA). The purpose of this study was to examine how adolescent PA changed during school closures, to identify the key barriers and facilitators for these changes during lockdown and to use this information to understand how to manage future crises' situations positively to prevent physical inactivity. Methods Irish adolescents ( $\mathrm{N}=1214$; ages $12-18$ years) participated in an online cross-sectional study during April 2020, including items on PA level, changes in PA and reasons for change in an open-ended format. Numeric analyses were through multiple binary logistic regressions, stratified by changes in PA during lockdown and inductive analysis of open coding of text responses.

Results Adolescents reported they did less PA (50\%), no change $(30 \%)$ or did more PA during lockdown $(20 \%)$. Adolescents who did less PA were more likely to be overweight $(\mathrm{OR}=1.8, \mathrm{Cl}=1.2-2.7)$ or obese $(\mathrm{OR}=2.2$, $\mathrm{Cl}=1.2-4.0$ ) and less likely to have strong prior PA habits $(\mathrm{OR}=0.4, \mathrm{Cl}=0.2-0.6)$. The most cited barriers to PA were coronavirus, club training cancelled and time. Strong associations for doing more PA included participation in strengthening exercises at least three times in the past 7 days $(\mathrm{OR}=1.7, \mathrm{Cl}=1.3-2.4)$; facilitators were more time, coronavirus and no school.

Conclusion COVID-19 restrictions were both a barrier to and an opportunity for PA. Parents, schools, public health, communities and industries must collaborate to prevent physical inactivity at times of crisis, especially for vulnerable groups.

\section{BACKGROUND}

Closure of schools due to the COVID-19 pandemic put adolescents into the home environment in what is known as lockdown. Without access to physical education (PE), active commuting or other school-related physical activity (PA) opportunities, adolescents are at risk of weight gain, lowered physical functioning and increased screen time use. ${ }^{1}{ }^{2}$ Furthermore, the lack of exposure to nature, exercise and interpersonal relationships can lead to reduced well-being. ${ }^{3}$ With evidence to support the protective factors from PA via boosting an individual's immune response to viruses, ${ }^{4} 5$ improved physical, social and

\section{Summary box}

Why we did it

- Social distancing restrictions from COVID-19 included closures of schools and sport clubs, reducing adolescent opportunities for physical activity (PA). The direct impact was decreased PA levels for many adolescents, although some managed to increase their PA during this challenging time. This paper provides insights into changes in adolescent PA behaviour during lockdown and the key barriers and facilitators influencing this change. Implications for practice for schools, families, communities, policy and industry are further highlighted.

\section{What are the new findings}

- Half of the students reported doing less physical activity (PA) than normal.

- One in five students reported doing more PA during lockdown, despite the very restrictive movement limitations.

- COVID-19 had the most impact on PA among the least physically active and adolescents who were overweight, obese or had poor prior PA habits.

- Recommendations for mitigating the impact of social distancing on adolescent PA involve schools, communities, public health and industry adopting more adolescent-friendly approaches to messaging, restrictions and provision of ageappropriate resources.

How might it impact clinical practice in the future

- Data on physical activity (PA) and the effects from COVID-19 are lacking. These findings support the call for teachers, organized sports professionals, public health officials, communities and industry to organize and create opportunities for adolescents to be physically active, when rules of school closures and physical distance restrictions are in place. In addition, messages to promote PA should be targeted to parents and particularly for adolescents who are overweight or obese as they were the most affected group. Encourage the use of existing infrastructure to exercise daily through traditional activities such as walking or cycling, as well as take up opportunities to connect with others during online PA sessions. 
mental health, ${ }^{6}$ and with the uncertainty of how long school closures will last or could happen again, information about the changes in PA behaviours among adolescents during lockdown is urgently needed. ${ }^{7}$

Currently, global figures indicate that the proportion of adolescents meeting PA guidelines is low (approximately $20 \%){ }^{8}$ Adolescence is a transitionary period of physical, social and cognitive changes, and a decline in PA occurs at this time. ${ }^{9} 10$ This is of concern as PA behaviours continue into adulthood. ${ }^{11}{ }^{12}$ Currently, there is a lack of data on the relationship between PA and the effects of the COVID-19 pandemic. Limited data from PA trackers during lockdown ${ }^{13}$ indicate that there has been a reduction in PA globally. However, few adolescents use PA trackers, ${ }^{14}$ leaving large proportion of adolescents' PA behaviours under-reported. Data from Chinese adolescents saw a three-fold decrease in PA during lockdown. ${ }^{15}$ In other studies, participation in sports during lockdown reduced (mean difference $=2.3$, $\mathrm{SD}=4.6$ days) among Italian overweight or obese adolescents, ${ }^{16}$ and only $2.6 \%$ of children and youth met the Canadian 24-Hour Movement Behaviour Guidelines, compared to rates between $12 \%$ and $17 \%$ before lockdown. ${ }^{17}$ Conclusions from Canada highlighted that a lack of parental support was associated with not meeting the daily moderate-to-vigorous PA (MVPA) guidelines. ${ }^{18}$ Further data on reasons to effectively promote future health, data on the reasons adolescents give for PA or inactivity during COVID-19 restrictions are needed. ${ }^{7} 1920$

In the most recent research, ${ }^{15-17}$ information about individuals' levels of PA prior to COVID-19 was missing, and no known study has yet explored the reasons for increases or decreases in PA during lockdown from the perspective of the adolescent. ${ }^{19}$ The purpose of this study was to report how adolescent PA levels changed as a direct result of the COVID-19 emergency, identifying who did more, the same or less PA; to determine how prior PA habits were predictors of these changes in PA; and to identify the key barriers and facilitators for changes in PA during lockdown.

\section{METHODS}

\section{Procedures}

The study was approved by the Ethical research committee of the Faculty of Education and Health Sciences, University of Limerick as part of the Second-level active school flag (ASF) feasibility study. ${ }^{21}$ The ASF is a Department of Education and Skills initiative, supported by Healthy Ireland, and developed using a codesign approach with students, teachers, parents and the local community. Both parent consent through passive consent and child assent were provided. Completion of surveys was carried out anonymously with no consequences for not taking part. Teachers and school management assisted the research team in recruiting students. An online survey link was subsequently sent to students via class tutors, and surveys were completed in April 2020.

There were six schools (two girls only, one boys only, three mixed, of which two were designated disadvantage schools) with planned data collection in May 2020. COVID-19 ended the academic year prematurely, and the survey was administered early into lockdown with teachers as the point of contact. A response rate of $33 \%$ $(\mathrm{n}=1551)$ was achieved, and following data cleaning (ie, students started but did not continue or provided unusable data), the final response rate was $26 \%(\mathrm{n}=1214)$.

\section{Instruments}

Adolescents were asked to report their gender, school year, height and weight in the self-report online survey. Cole's body mass index (BMI) adjustments for cutoffs for normal, overweight and obese were applied. ${ }^{22}$

\section{Physical activity}

MVPA was measured through the past 7-day (number of days of at least 60 min of MVPA) item from the PA PACE+ instrument. ${ }^{23}$ To allow examination of small changes in PA behaviour across a 7-day period, the scale was divided into four categories of activity status; inactive (0-2 days); somewhat active (3-4 days), highly active (5-6 days) and daily active ( 7 days; meeting MVPA guidelines). ${ }^{6}$ The instrument is validated against accelerometers $(\mathrm{r}=0.27-0.39),{ }^{24}$ has moderate agreement for test-retest reliability (intraclass correlation coefficient, ICC $=0.50)^{25}$ and recommended for use of large survey studies. ${ }^{26}$

A single item assessing frequency of 'Exercises that may strengthen your muscles, such as push-ups, sit-ups, weight lifting or heavy yard work during the past 7 days?' was asked with $0-7$ days as response options. The eight categories were dichotomized into $<3$ times/week and $\geq 3$ times to reflect meeting the PAGL of $\geq 3$ times/week. ${ }^{6}$ There was acceptable face validity from instrument testing with a student panel, and other psychometric properties have not been reported.

\section{Change in PA during lockdown}

Adolescents responded to "was the amount of PA you did in the last 7 days typical of the amount that you would normally do?' with 'yes', 'no, I usually do more' or 'no, I usually do less', and data were presented quantitatively. Students who responded to either 'no' option were asked, 'If no, why was this week unusual?' and provided open-ended responses, these data were analysed qualitatively. This item has been used in other Irish monitoring studies. ${ }^{27}$

\section{School transport}

Mode of transport usually used to travel to and from school was assessed via five options: walk, bicycle, car, bus and train. Two groups were created, (1) passive: cars, bus and trains and (2) active: walk and bicycle. This item has been used in other Irish monitoring studies ${ }^{27}$ and is reliable $(\mathrm{ICC}=0.66) .{ }^{28}$

\section{Prior PA habits}

Prior PA habits were created from combining three frequency PA behavioural variables in different contexts; PE, lunchtime activities, and after-school sports or physical activities as used in previous monitoring studies. ${ }^{27} \mathrm{PE}$ 
range was a 5-point scale from Never (1) to Always (5), whereas lunchtime and after-school activities range was a 7-point scale from Never (1) to 4 or more days per week (7). The sum score was divided into three even groups to represent prior weak, moderate and strong PA habits (Cronbach's Alpha=0.54).

\section{Analyses}

Quantitative

Statistical analyses were carried out through multiple $\chi^{2}$ tests of independence for determining differences from the independent variables (gender, BMI, strengthening exercises, transport mode and PA habits) by activity status (inactive, somewhat active, highly active and daily active) using SPSS 25.0. Data were then stratified by binary groups of (a) less PA (1) versus other (0), (b) no change (1) versus some change (0) or (c) more PA (1) versus other (0), and repeated multivariate binary logistic regressions were performed with all independent variables, after controlling for age to investigate the adjusted ORs of predictors to PA behaviour during lockdown. Alpha was set at 0.05 and strength of associations was reported by the $95 \%$ CIs.

\section{Qualitative}

Inductive open coding was carried out manually on openended survey responses to enable a more in-depth understanding of PA barriers and facilitators during lockdown. ${ }^{29}$ Similar terms were grouped into broader themes, and data from student's responses that covered more than one theme were reported accordingly. Data were analysed by activity status, and within each activity, category themes were further stratified into 'more active than usual' and 'less active than usual' groups, which presented some themes as both facilitators and barrier, respectively. Examples of coding can be found in online supplemental table 1.

\section{RESULTS}

\section{Descriptive results}

In table 1 , most participants were female $(72 \%)$, from junior cycle (12-15 yr: 57\%) and from nondisadvantaged schools (72\%). Three quarters $(77 \%)$ were classified with normal BMI, $15.6 \%$ overweight and $8.2 \%$ obese. A quarter of students $(25 \%)$ were inactive, a third (34\%) were somewhat active, a quarter $(26 \%)$ were active and $15 \%$ were daily active. The proportion of students who took part in strengthening exercises $\geq 3$ times a week and had strong prior PA habits increased linearly as PA levels increased. A third (36\%) usually commuted actively to and from school.

Half the adolescents $(49.7 \%)$ reported doing less PA during the lockdown period (figure 1). Almost a third $(31.2 \%)$ reported doing the same amount of PA, and one in five $(19.1 \%)$ reported they did more PA during lockdown. As activity status lowered, the proportion negatively impacted by COVID-19 increased, and vice versa for highly active children $\left(\chi^{2}{ }_{6} \mathrm{df}=85.2, \mathrm{p}<0.001\right)$. The open- ended responses $(\mathrm{N}=947)$ were grouped into 15 themes. It was common for adolescents to provide multiple barriers or facilitators in their answers, and three themes were coded both as barriers and facilitators to PA: coronavirus, time and no school (table 2).

\section{Less PA during lockdown}

Twelve themes explained the reduction in PA during lockdown. These were coronavirus, club training cancelled, health concerns, low motivation, no school, too much schoolwork, closed facilities, lack of resources, mental health, time, lack of routine and other. Of the top seven barriers, restrictions from COVID-19 and club training cancelled were the most common across all activity groups (table 2). 'Because of corona virus (sic) all sports are cancelled so it's [PA] only what you do by yourself' (daily active), 'Due to COVID-19 the sports I do is cancelled and I cannot go outside apart one walk a day' (inactive).

Adolescents who were overweight $(\mathrm{OR}=1.8, \mathrm{CI}=1.2$ 2.7) or obese $(\mathrm{OR}=2.2, \mathrm{CI}=1.2-4.0)$ were more likely than those who were normal weight to report less PA during lockdown (table 3). Inactive adolescents reported COVID-19 caused health concerns, leading to parents limiting adolescents' PA: 'I can't go outside for a walk due to quarantine and social distancing. My parents don't feel comfortable with me going outside due to coronavirus' (inactive). Among inactive adolescents, the decision to do something else was made easy: 'I was more eager to eat and binge Netflix, and sometimes I don't even want to go on walks' (inactive). Particularly, as schools were closed, reducing the places to be physically active: 'Because there was no school and I usually get my exercise in PE class' (inactive).

Adolescents with strong prior PA habits were less likely $(\mathrm{OR}=0.4, \mathrm{CI}=0.2-0.6)$ than those with weak PA habits to have reported less PA during lockdown. With school closures, PE, active travel and after-school PA opportunities were removed: 'Doing school online means that I don't get my usual exercise from walking to school each day, or my hockey trainings' (somewhat active). The online learning environment was seen as less conducive to PA, 'I normally do more it's just I have been sitting a lot due to online school' (highly active) or the negative impact of increased school workload, 'Had to get work done before I could go out and it was getting late by the time I got it done' (somewhat active) and 'I didn't have as much time due to studying and extra work' (highly active). No adolescent reported doing PE online as part of their schoolwork. The closure of facilities as part of lockdown was a barrier, 'Coronavirus stops me from accessing the facilities I usually need' (highly active). No access to the facilities also meant no access to their equipment, 'I normally go to a gym on a Monday, but I don't have the space or equipment to keep going with that training' (highly active). Furthermore, no longer having instruction from a coach led to adolescents being unsure of what to do, 'as I don't have anyone to tell me what to do as in a coach' (somewhat active). 
Table $1 \chi^{2}$ tests of independence of individual characteristics by PA frequency group

\begin{tabular}{|c|c|c|c|c|c|c|}
\hline & Inactive & Somewhat active & Active & Daily active & Total & \\
\hline & $\begin{array}{l}\mathrm{N}=308 \\
\%\end{array}$ & $\begin{array}{l}\mathrm{N}=410 \\
\%\end{array}$ & $\begin{array}{l}\mathrm{N}=316 \\
\%\end{array}$ & $\begin{array}{l}N=180 \\
\%\end{array}$ & $\begin{array}{l}N=1214 \\
\%\end{array}$ & $\begin{array}{l}\text { Chi-square } \\
\mathrm{P} \text { value }\end{array}$ \\
\hline Education level & & & & & & 0.096 \\
\hline Junior cycle & 51.3 & 59.5 & 58.5 & 60.6 & 57.3 & \\
\hline Senior cycle & 48.7 & 40.5 & 41.5 & 39.4 & 42.7 & \\
\hline Body Mass Index (BMI) & & & & & & 0.301 \\
\hline Normal & 76.2 & 74.7 & 76.4 & 82.9 & 76.7 & \\
\hline Overweight & 15.6 & 19.3 & 17.7 & 13.8 & 17.2 & \\
\hline Obese & 8.2 & 6.0 & 5.9 & 3.3 & 6.1 & \\
\hline Change in Physical Activity & & & & & & $<0.001$ \\
\hline Less in Lockdown & 71.8 & 54.6 & 36.4 & 23.9 & 49.7 & \\
\hline No Change & 18.2 & 29.5 & 36.7 & 47.8 & 31.2 & \\
\hline More in Lockdown & 10.1 & 15.9 & 26.9 & 28.3 & 19.1 & \\
\hline Strengthening exercises & & & & & & $<0.001$ \\
\hline$<3$ times/week & 85.1 & 56.2 & 30.3 & 19.1 & 51.2 & \\
\hline$\leq 3$ times/week & 14.9 & 43.8 & 69.7 & 80.9 & 48.8 & \\
\hline School transport & & & & & & 0.967 \\
\hline Passive & 64.2 & 64.2 & 62.7 & 64.7 & 63.9 & \\
\hline Active & 35.8 & 35.8 & 37.3 & 35.3 & 36.1 & \\
\hline Prior Physical Activity habits & & & & & & $<0.001$ \\
\hline Weak & 45.4 & 26.5 & 21.7 & 19.1 & 28.9 & \\
\hline Moderate & 38.1 & 38.6 & 37.9 & 32.0 & 37.3 & \\
\hline Strong & 16.6 & 34.9 & 40.4 & 48.9 & 33.8 & \\
\hline
\end{tabular}

Total $(n=1214)$

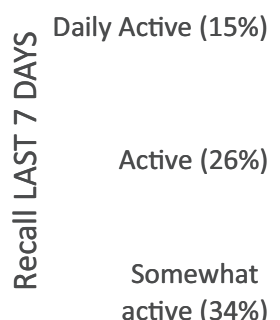

Inactive (25\%)

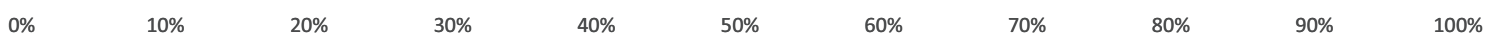

Figure 1 Distribution of perceived changes in MVPA according to last 7 days MVPA. 
Table 2 Percentage of themes as barriers or facilitators by PA categories

$\%$ Barriers ('who did less'during lockdown) \%

\begin{tabular}{|c|c|c|c|c|c|c|c|c|c|c|c|}
\hline \multirow[b]{2}{*}{ Theme } & \multirow{2}{*}{$\begin{array}{l}\frac{\%}{1} \\
\text { All }\end{array}$} & \multicolumn{5}{|c|}{ Barriers ('who did less'during lockdown) \% } & \multicolumn{5}{|c|}{ Facilitators ('who did more' during lockdown) \% } \\
\hline & & Total & Inactive & $\begin{array}{l}\text { Somewhat } \\
\text { active }\end{array}$ & Active & $\begin{array}{l}\text { Daily } \\
\text { active }\end{array}$ & Total & Inactive & $\begin{array}{l}\text { Somewhat } \\
\text { active }\end{array}$ & Active & $\begin{array}{l}\text { Daily } \\
\text { active }\end{array}$ \\
\hline Total $(\mathrm{N})$ & 947 & 690 & 260 & 249 & 131 & 50 & 257 & 18 & 66 & 116 & 57 \\
\hline Coronavirus & 45 & 53 & 57 & 49 & 49 & 44 & 23 & 50 & 23 & 20 & 24 \\
\hline $\begin{array}{l}\text { Club training } \\
\text { cancelled }\end{array}$ & 12 & 17 & 8 & 19 & 27 & 24 & & & & & \\
\hline Time & 9 & 2 & 1 & 3 & 2 & 0 & 27 & 6 & 33 & 28 & 26 \\
\hline No school & 7 & 4 & 5 & 4 & 2 & 6 & 14 & 0 & 8 & 17 & 24 \\
\hline Closed facilities & 5 & 7 & 5 & 8 & 7 & 8 & & & & & \\
\hline $\begin{array}{l}\text { Too much } \\
\text { schoolwork }\end{array}$ & 4 & 5 & 5 & 6 & 5 & 2 & & & & & \\
\hline Stay healthy & 3 & & & & & & 12 & 17 & 11 & 18 & 2 \\
\hline Lack of motivation & 3 & 4 & 7 & 3 & 1 & 2 & & & & & \\
\hline Nothing else to do & 2 & & & & & & 7 & 11 & 8 & 5 & 9 \\
\hline
\end{tabular}

or bored

\begin{tabular}{llllllllllll} 
Health issues & 2 & 2 & 2 & 3 & 2 & 4 & & & & \\
Going on walks & 1 & & & & & & 5 & 11 & 6 & 5 & 3 \\
Lack of resources & 1 & 2 & 1 & 2 & 2 & 0 & & & & \\
Needed to go out & 1 & & & & & & 4 & 0 & 5 & 3 \\
Lack of routine & 1 & 1 & 1 & 0 & 2 & 0 & & & & & \\
Mental health & 0 & 1 & 1 & 0 & 0 & 0 & & & & \\
Other & 4 & 3 & 3 & 1 & 2 & 10 & 6 & 6 & 8 & 3 & 7 \\
\hline
\end{tabular}

\section{No change in PA during lockdown}

Females were less likely $(\mathrm{OR}=0.7, \mathrm{CI}=0.5-0.9)$ to report the same levels of PA as usual during lockdown than males. Similarly, those who engaged in strength training at least three times per week $(\mathrm{OR}=0.6, \mathrm{CI}=0.4-0.8)$ were less likely to report the same levels of PA during lockdown in comparison to those who participated in strength training less often. No open-ended questions were asked from his group.

\section{More PA during lockdown}

There were eight themes on facilitators. These were: coronavirus, time, no school, nothing else to do, stay healthy, going on walks, needed to go out and other. Common facilitators for engaging in more PA across all MVPA groups were coronavirus, stay healthy and nothing else to do (table 2). In contrast to the other two groups (less than normal, the same), there were positive associations between PA level and doing strengthening exercises at least three times a week $(\mathrm{OR}=1.7, \mathrm{CI}=1.3-2.4)$. A way that adolescents reported engaging in exercises during lockdown was through, 'many celebrities [who] do live workouts which I participate in' (somewhat active). Awareness of health benefits from PA was commonly reported: 'I had a lot of extra time on my hands so I decided to be more active and improve my health' (highly active).

Those who actively commuted to school $(\mathrm{OR}=1.6$, CI=1.2-2.2) reported more PA during lockdown. (table 3). Although the opportunity to commute to school was removed, adolescents were encouraged to walk and this increased their PA: 'I went walking everyday with my family because we can't leave the house for any other reason' (highly active). This tied in with their need to go outside, 'Needed to get out for fresh air because I was stuck inside all day' (daily active).

Coronavirus was a common facilitator for PA: 'COVID19 and road closures meant our road was quieter' (somewhat active) and allowed adolescents to go out in their neighbourhood. 'No school' was considered as a way for adolescents to do other activities, such as PA: 'Having such a lengthy time off school has allowed me to focus on my physicality and health more' (highly active). In addition, the availability of more time was considered a facilitator to PA 'Because I don't have school so I have more time to do home workouts and go for walks' (somewhat active), which was supported by the evidence that strong PA habits were associated with reporting more $\mathrm{PA}$ during lockdown $(\mathrm{OR}=2.6$, $\mathrm{CI}=1.7-3.7)$.

Nothing else to do was also commonly reported; 'We are stuck in the house more so I am getting out [exercising] a bit more because there is nothing else to do and I don't want to have bad health or mental health' (inactive). Furthermore, PA became a method of entertainment, with limited other activities allowed, 'I did more exercise as a way to entertain myself' (highly active). 
Table 3 Adjusted OR for characteristics for changes in PA during lockdown

\begin{tabular}{|c|c|c|c|c|c|c|c|c|c|c|c|c|}
\hline & \multicolumn{4}{|c|}{ Less PA during lockdown } & \multicolumn{4}{|c|}{ No change } & \multicolumn{4}{|c|}{ More PA during lockdown } \\
\hline & $P$ value & OR & LCI & $\mathrm{UCl}$ & $P$ value & OR & LCI & $\mathrm{UCI}$ & $P$ value & OR & LCI & $\mathrm{UCl}$ \\
\hline \multicolumn{13}{|l|}{ Gender } \\
\hline Male & & REF & & & & REF & & & & REF & & \\
\hline Female & 0.30 & 1.21 & 0.84 & 1.75 & 0.01 & 0.69 & 0.51 & 0.92 & 0.12 & 1.27 & 0.94 & 1.72 \\
\hline \multicolumn{13}{|l|}{ BMI category } \\
\hline Normal & & REF & & & & REF & & & & REF & & \\
\hline Overweight & $<0.01$ & 1.79 & 1.19 & 2.69 & 0.08 & 0.71 & 0.48 & 1.04 & 0.47 & 0.88 & 0.61 & 1.26 \\
\hline Obese & 0.02 & 2.16 & 1.16 & 4.01 & 0.68 & 0.89 & 0.50 & 1.58 & 0.07 & 0.59 & 0.33 & 1.04 \\
\hline \multicolumn{13}{|l|}{ Strength } \\
\hline$<3 /$ week & & REF & & & & REF & & & & REF & & \\
\hline$\geq 3 /$ week & 0.88 & 0.96 & 0.67 & 1.39 & $<0.01$ & 0.59 & 0.44 & 0.81 & $<0.01$ & 1.73 & 1.27 & 2.37 \\
\hline \multicolumn{13}{|l|}{ School transport } \\
\hline Passive & & REF & & & & REF & & & & REF & & \\
\hline Active & 0.01 & 0.62 & 0.43 & 0.88 & 0.33 & 0.87 & 0.65 & 1.16 & $<0.01$ & 1.59 & 1.19 & 2.11 \\
\hline \multicolumn{13}{|l|}{ Prior PA habits } \\
\hline Weak & & REF & & & & & & & & REF & & \\
\hline Moderate & 0.24 & 0.79 & 0.53 & 1.17 & 0.91 & 0.98 & 0.69 & 1.39 & 0.30 & 1.20 & 0.85 & 1.70 \\
\hline Strong & $<0.001$ & 0.38 & 0.23 & 0.60 & 0.19 & 0.78 & 0.53 & 1.14 & $<0.001$ & 2.55 & 1.74 & 3.73 \\
\hline Nagelkerke $\mathrm{R}^{2}$ & 0.14 & & & & 0.08 & & & & 0.22 & & & \\
\hline
\end{tabular}

Adjusted OR after controlling for age.

$\mathrm{BMI}$, body mass index; LCl, lower $95 \% \mathrm{Cl}$; PA, physical activity; REF, reference category; $\mathrm{UCI}$, upper $95 \% \mathrm{CI}$.

\section{DISCUSSION}

\section{Main findings}

In this study, half the adolescents reported they did less, a third reported that they did the same and one in five reported they did more PA than usual when COVID-19 restrictions were in place. This study gathered reasons from adolescents to explain their PA changes during the spring 2020 national lockdown in Ireland, providing insights into the challenges and coping strategies they employed. These findings can be used to manage future crises' situations positively to prevent physical inactivity.

The prevalence of change in PA is similar to reports of increased adolescent inactivity during lockdowns in Canada, ${ }^{17}$ China $^{15}$ and Italy ${ }^{16}$ confirming the need for innovative action from multiple stakeholders. ${ }^{2}$ As with reports from Italy, ${ }^{16}$ decrease in PA behaviour was more severe among the obese, the overweight and those adolescents with poor PA habits prior to COVID-19. Overweight and obesity were strong predictors for doing less PA during lockdown, putting individuals at risk of double trouble, since both obesity and physical inactivity increase the mortality risks from respiratory diseases. ${ }^{30}$

Coronavirus as mentioned by the adolescents, and sometimes referred to as COVID-19, was the most influential barrier cited across all activity levels. Experiences of lockdown among adolescents have been reported as leading to more negative feelings, lack of personal space and a strain on social relationships, ${ }^{31}$ limiting the willingness and possibilities to remain physically active. Furthermore, $82 \%$ of individuals in a youth panel reported that they wanted more information on what to do indoors during the lockdown. ${ }^{32}$ Coronavirus was also reported as a facilitator for a quarter of adolescents, more frequently by inactive children than those in other activity categories. Lockdown presented opportunities for personal growth and family cohesion, ${ }^{33}$ with more time and no school as facilitators to take part in activities not done previously, like PA.

\section{Understanding how to mitigate the negative influence of COVID-19 on PA}

Two key, but interrelated barriers included club training cancellations and closed facilities. Clubs could facilitate a range of alternative activities like online coach-led PA sessions. In addition, top-down guidance from national sporting bodies to engage members into sports clubs to mitigate the COVID-19 impact. Continuous professional development opportunities and support groups ${ }^{34}$ for the majority of coaches require further research as professionals grappled with technology-based coaching methods. ${ }^{35}$

The Irish Department of Education and Skills recommended that adolescents should remain 'active and connected' during lockdown. ${ }^{36}$ The experience of coaches and teachers should be involved in creating content that encourages and supports readily available activities such as walking, cycling (that can be done safely within current guidance or at home) or following online exercise routines. ${ }^{30}{ }^{37}$ Scheduling of exercise classes, in the form 
of educational videos, ${ }^{38}$ with activity breaks in the day can be effective ways to promote PA. ${ }^{39}$ Adolescents reported several school-related barriers: too much schoolwork, lack of time after doing schoolwork and lost opportunities to participate in school sports. These barriers can alter habitual behaviour, which is crucial for students to selfenact their behaviour ${ }^{40}$ in unusual circumstances like a lockdown. Not all teachers have been exposed to technology for $\mathrm{PE}^{41}$ highlighting a gap in professional development ${ }^{42}$ and the untrained way of teaching and learning may have influenced longer school hours. The PE department with sports clubs has important roles in promoting lifelong and leisure-time PA. ${ }^{43}$ Going forward, the education and sports sector should identify and recommend high-quality, age-appropriate $\mathrm{PA}$ or $\mathrm{PE}$ apps, and aim to establish school-day routines conducive to encouraging PA through routine, for example, active breaks, or through learning, for example, online PE classes.

Industry also has a role to play. Other cited barriers to PA by adolescents during COVID-19 lockdown were competing priorities and lack of home PA equipment. The competing priorities referred to the use of streaming services by adolescents, where access to streaming of TV programmes and movies encouraged binge-watching, competing with $\mathrm{PA}$ as a time-use activity. ${ }^{44}$ A public health strategy during a pandemic could require streaming companies to routinely interrupt the streaming of programmes with short, highly appealing celebrity-led PA routines or by promoting programmes that encourage PA. Furthermore, a system is needed to subsidise home-based PA equipment for families.

Other barriers identified by the adolescents were psychological (health concerns and low motivation). The 'stay at home' health messages could have parallel adolescent health promotion-relevant messages on the shortterm health gain from PA despite lockdown conditions. ${ }^{45}$ Public health agencies, as trusted sources, must consider cognitive and behavioural strategies to help those most at risk, particularly the inactive overweight or obese adolescents. ${ }^{46}$

\section{Understanding how to maximize the positives influence of COVID-19 on PA}

More male than female students reported unchanged levels of PA during lockdown, suggesting gender differences in stabilization of PA. ${ }^{47}$ Furthermore, adolescents with prior strong PA habits were over two times more likely to report more PA during lockdown than those with weak PA habits. This emphasizes the importance of habit formation. ${ }^{48}$ Doing something worthwhile is a known factor to PA decision-making, ${ }^{49}$ and this can be used to reinforce PA habits to build resilience against the shock from the COVID-19 emergency. ${ }^{20}$ The positive associations established between 'doing more PA during lockdown' with active travel supports schools being located within close proximity to residential homes ${ }^{50}$ and impacted adolescents' ability to be more active during the pandemic. The combined positive associations of doing sufficient amount of strengthening exercises with usual active transportation and strong PA habits confirms the basis of social-ecological models to promote PA. ${ }^{51}$ Having more time and no school were facilitators for more active than inactive adolescents. Being bored and having nothing else to do were reported facilitators for PA, this provides a mandate and a call to action for all stakeholders to be ready to help adolescents explore fun ways to stay active at home.

One in five students reported more PA during lockdown and often stated parental support was a facilitator. Parents with less capabilities to support their children home have been found to also take part in less PA, ${ }^{18}$ and more encouragement for family-based activities is needed. Through a better understanding of PA, parents themselves who take up the new opportunities to participate in more PA during lockdown ${ }^{17}$ may overcome the perceived barriers from parental restrictions reported in our study.

\section{Study limitations}

There are study limitations to consider. The openended text was only completed by students who reported changes in their MVPA levels, giving insights only on change and not the phenomenon of behaviour during lockdown. These ASF schools have been exposed to ASF, a PA intervention for 6 months (3 schools) and 18 months (3 schools). Consequently, levels of PA may reflect the impact of an intervention, however the learning from how these adolescents coped with the pandemic and its impact on their PA is still relevant and informative. Items were selfreported and some bias may exist. Administration of surveys was carried out without direct supervision, although a short video and instructions were given to the student to complete in an area without distractions. A trade-off between convenience to complete the survey (on a mobile phone) and richness of information was made in favour of allowing students to complete the survey with little hindrance.

\section{CONCLUSIONS}

Half the adolescents reported less PA than normal, hence progress towards national ${ }^{52}$ and WHO targets to decrease inactivity by $15 \%$ by $2030^{8}$ have been severely hampered by the COVID-19 pandemic. Barriers were varied, but surmountable and unexpected opportunities for increased PA during COVID restrictions emerged. This lack of knowledge or sense of urgency requires long-term responses that include cooperation between parents, teachers, policymakers, communities and industry. Tailoring interventions to promote PA opportunities that feature in the behavioural epidemiological framework ${ }^{7}$ may help the realignment to meet the WHO targets following changes in PA during COVID-19 lockdown. ${ }^{53-55}$ 
Twitter Kwok Ng @KwokWNg, Jemima Cooper @JemimaACooper, Fiona McHale @FionaMcHale and Catherine Woods @CatherineBWoods.

Acknowledgements Sarah Taylor, Maeve Conneely, Karen Cotter and Donal 0 'Shea. ASF coordinators, school principals and teachers, and students involved in ASF.

Contributors KN: Conceptualization, Methodology, Validation, Formal Analysis, Investigation, Data Curation, Writing Original Draft, Writing Review \& Editing and Visualization; JCO: Conceptualization, Methodology, Formal Analysis, Investigation, Writing Review \& Editing and Visualization; FM: Investigation and Writing Review \& Editing; JCL: Investigation and Writing Review \& Editing; CW: Conceptualization, Methodology, Investigation, Writing Review \& Editing, Funding Acquisition.

Funding Second-level ASF was funded by Mayo Education Centre, St. Vincent's Hospital Trust, and Healthy Ireland and had no role in the data analyses.

Competing interests None declared.

Ethics approval Approved by the last author's institutional ethical committee2018 10_18 EH.

Provenance and peer review Not commissioned; externally peer reviewed.

Data availability statement Available upon request.

Supplemental material This content has been supplied by the author(s). It has not been vetted by BMJ Publishing Group Limited (BMJ) and may not have been peerreviewed. Any opinions or recommendations discussed are solely those of the author(s) and are not endorsed by BMJ. BMJ disclaims all liability and responsibility arising from any reliance placed on the content. Where the content includes any translated material, BMJ does not warrant the accuracy and reliability of the translations (including but not limited to local regulations, clinical guidelines, terminology, drug names and drug dosages), and is not responsible for any error and/or omissions arising from translation and adaptation or otherwise.

Open access This is an open access article distributed in accordance with the Creative Commons Attribution Non Commercial (CC BY-NC 4.0) license, which permits others to distribute, remix, adapt, build upon this work non-commercially, and license their derivative works on different terms, provided the original work is properly cited, appropriate credit is given, any changes made indicated, and the use is non-commercial. See: http://creativecommons.org/licenses/by-nc/4.0/.

\section{ORCID iDs}

Kwok Ng http://orcid.org/0000-0002-5461-7706

Jemima Cooper http://orcid.org/0000-0001-5102-7279

Catherine Woods http://orcid org/0000-0002-0892-6591

\section{REFERENCES}

1 Rundle AG, Park Y, Herbstman JB, et al. 19: related school closings and risk of weight gain among children. Obesity 2020;28:1008-9.

2 Guan H, Okely AD, Aguilar-Farias N, et al. Promoting healthy movement behaviours among children during the COVID-19 pandemic. Lancet Child Adolesc Health 2020;4:416-8.

3 Lades LK, Laffan K, Daly M, et al. Daily emotional well-being during the COVID-19 pandemic. Public Policy 2020.

4 Nieman DC, Wentz LM. The compelling link between physical activity and the body's defense system. J Sport Health Sci 2019;8:201-17.

5 Laddu DR, Lavie CJ, Phillips SA, et al. Physical activity for immunity protection: inoculating populations with healthy living medicine in preparation for the next pandemic. Prog Cardiovasc Dis 2020;S00330620:30078-5

6 Physical Activity Guidelines Advisory Committee. 2018 physical activity guidelines advisory committee scientific report. 2018.

7 Sallis JF, Adlakha D, Oyeyemi A, et al. An international physical activity and public health research agenda to inform COVID-19 policies and practices. J Sport Health Sci 2020;S2095-2546(20)30064-8.

8 Guthold R, Stevens GA, Riley LM, et al. Global trends in insufficient physical activity among adolescents: a pooled analysis of 298 population-based surveys with 1.6 million participants. Lancet Child Adolesc Health 2020;4:23-35

9 Dumith SC, Gigante DP, Domingues MR, et al. Physical activity change during adolescence: a systematic review and a pooled analysis. Int J Epidemiol 2011;40:685-98.

10 Sawyer SM, Azzopardi PS, Wickremarathne D, et al. The age of adolescence. Lancet Child Adolesc Health 2018;2:223-8.
11 Telama R, Yang X, Leskinen E, et al. Tracking of physical activity from early children through youth into adulthood. Med Sci Sports Exerc 2014;46:955-62.

12 Hayes G, Dowd KP, MacDonncha C, et al. Tracking of physical activity and sedentary behavior from adolescence to young adulthood: a systematic literature review. J Adoles Health 2019;65:446-54.

13 Pépin JL, Bruno RM, Yang R, et al. Wearable activity trackers for monitoring adherence to home confinement during the COVID-19 pandemic worldwide: data aggregation and analysis. J Med Internet Res 2020;22:e19787.

$14 \mathrm{Ng} \mathrm{KW}$, Kokko S, Tammelin TH, et al. Clusters of adolescent physical activity tracker patterns and their associations with physical activity behaviors in finland and ireland: cross-sectional study. J Med Internet Res 2020;22:1-15.

15 Xiang M, Zhang Z, Kuwahara K. Impact of COVID-19 pandemic on children and adolescents' lifestyle behavior larger than expected. Prog Cardiovasc Dis 2020;S0033-0620:30096-7.

16 Pietrobelli A, Pecoraro L, Ferruzzi A, et al. Effects of COVID-19 lockdown on lifestyle behaviors in children with obesity living in verona, italy: a longitudinal study. Obesity 2020;28:1382-5.

17 Moore SA, Faulkner G, Rhodes RE, et al. Impact of the COVID-19 virus outbreak on movement and play behaviours of canadian children and youth: a national survey. Int J Behav Nutr Phys Act 2020;17:85

18 Guerrero MD, Vanderloo LM, Rhodes RE, et al. Canadian children's and youth's adherence to the 24-h movement guidelines during the COVID-19 pandemic: a decision tree analysis. J Sport Health Sci 2020;9:313-21.

19 Andersen CS, Dolva A, Children's perspective on their right to participate in decision-making according to the united nations convention on the rights of the child article 12. Phys Occup Ther Pediatr 2015;3:218-230.

20 Giovannini E, Benczur P, Campolongo F, et al. Time for transformative resilience: the COVID-19 emergency. 2020. EUR 30179 EN.

$21 \mathrm{Ng} \mathrm{KW}$, McHale F, Cotter K, et al. Feasibility study of the secondary level active school flag programme: study protocol. J Functional Morphol Kinesiol 2019;4:1-16.

22 Cole TJ, Bellizzi MC, Flegal KM, et al. Establishing a standard definition for child overweight and obesity worldwide: international survey. BMJ 2000;320:1240.

23 Prochaska JJ, Sallis JF, Long B. A physical activity screening measure for use with adolescents in primary care. Arch Pediatr Adolesc Med 2001;155:554-9.

24 Hardie Murphy M, Rowe DA, Belton S, et al. Validity of a two-item physical activity questionnaire for assessing attainment of physical activity guidelines in youth. BMC Public Health 2015;15:1080.

$25 \mathrm{Ng} \mathrm{KW}$, Hämylä R, Tynjälä J, et al. Test-retest reliability of adolescents self-reported physical activity item in two consecutive surveys. Arch Public Health 2019;77:9.

26 Biddle SJH, Gorely T, Pearson N, et al. An assessment of self-reported physical activity instruments in young people for population surveillance: project ALPHA. Int J Behav Nutr Phys Act 2011;8:1.

27 Woods CB, Powell C, Saunders JA, et al. The children's sport participation and physical activity study 2018 (CSPPA 2018). Limerick, Ireland; Dublin, Ireland; Belfast, Northern Ireland: Department of Physical Education and Sport Sciences, University of Limerick; Sport Ireland and Healthy Ireland; Sport Northern Ireland. 2018. Available https://www.sportireland.ie/Research/ CSPPA\%20Final\%20Report.pdf

28 Woods CB, Nelson NM, O'Gorman DJ, et al. The take PART study (physical activity research for teenagers): rationale and methods. J Phys Act Health 2009;6:170-7.

29 St John W, Johnson P. The pros and cons of data analysis software for qualitative research. J Nurs Scholarsh 2000;32:393-7.

30 Hudson GM, Sprow K. Promoting physical activity during the COVID-19 pandemic: implications for obesity and chronic disease management. J Phys Act Health 2020;17:685-7.

31 Leavey C, Eastaugh A, Kane M. Generation COVID-19; building the case to protect young people's future health. London, UK: Health Foundation, 2020.

32 Burgess R, Nisbet E, Macdonald L. LockdownLowdown - what young people in scotland are thinking about COVID-19. Updated 2020. Available https://www.youthlinkscotland.org/media/4486/lockdownlowdown-final-report.pdf

33 Fegert JM, Vitiello B, Plener PL, et al. Challenges and burden of the coronavirus 2019 (COVID-19) pandemic for child and adolescent mental health: a narrative review to highlight clinical and research needs in the acute phase and the long return to normality. Child Adolesc Psychiatry Ment Health 2020;14:20.

34 Bertram R, Culver DM, Gilbert W. Creating value in a sport coach community of practice: a collaborative inquiry. ISCJ 2016;3:2-16. 
35 Evans AB, Blackwell J, Dolan P, et al. Sport in the face of the COVID-19 pandemic: towards an agenda for research in the sociology of sport. Eur J Sport Soc 2020;17:85-95.

36 National Educational Psychological Service. NEPS advice \& resources for keeping children and young people well during covid-19. Updated 2020. Available http://archive.vn/VtcP9

37 Wang G, Zhang Y, Zhao J, et al. Mitigate the effects of home confinement on children during the COVID-19 outbreak. Lancet (London, England) 2020;395:945-7.

38 Mason F, Farley A, Pallan M, et al. Effectiveness of a brief behavioural intervention to prevent weight gain over the christmas holiday period: randomised controlled trial. BMJ 2018:363:k4867.

39 Brazendale K, Beets MW, Weaver RG, et al. Understanding differences between summer vs. school obesogenic behaviors of children: the structured days hypothesis. Int J Behav Nutr Phys Act 2017;14:100.

40 Knittle K, Heino M, Marques MM, et al. The compendium of self-enactable techniques to change and self-manage motivation and behaviour v.1.0. Nat Hum Behav 2020;4:215-23.

41 Gawrisch DP, Richards KA, Killian CM. Integrating technology in physical education teacher education: a socialization perspective. Quest 2020;72:260-277.

42 O'Brien W, Adamakis M, O'Brien N, et al. Implications for european physical education teacher education during the COVID-19 pandemic: a cross-institutional SWOT analysis. Eur J Teach Educ 2020;43:503-22.

43 Hagger MS. The trans-contextual model of motivation: An integrated multi-theory model to explain the processes of motivational transfer across context. [Doctoral Dissertation]. University of Jyväskylä. (Studies in Sport, Physical Education and Health), 2014.

44 Thomas G, Bennie JA, De Cocker K, et al. A descriptive epidemiology of screen-based devices by children and adolescents: a scoping review of 130 surveillance studies since 2000 . Child Indic Res 2020;13:935-950.
45 Williamson C, Baker G, Mutrie N, et al. Get the message? A scoping review of physical activity messaging. Int J Behav Nutr Phys Act 2020;17:51.

46 Mutrie N, Woods CB. How can we get people to become more active? A problem waiting to be solved. In: McKenna J, Riddoch C, eds. Perspectives on health and exercise. 1st Ed edn. Basingstoke: Palgrave Macmillan, 2003: 129-52.

47 Norman GJ, Vaughn AA, Roesch SC, et al. Development of decisional balance and self-efficacy measures for adolescent sedentary behaviors. Psychol Health 2004;19:561-75.

48 Gardner B. A review and analysis of the use of 'habit' in understanding, predicting and influencing health-related behaviour. Health Psychol Rev 2015;9:277-95.

49 Tannehill D, MacPhail A, Walsh J, et al. What young people say about physical activity: the children's sport participation and physical activity (CSPPA) study. Sport Edu Soc 2015;20:442-62.

50 Nelson NM, Foley E, O'Gorman DJ, et al. Active commuting to school: how far is too far? Int J Behav Nutr Phys Act 2008;5:1.

51 Stankov I, Olds T, Cargo M. Overweight and obese adolescents what turns them off physical activity? Int J Behav Nutr Phys Act 2012;9:53.

52 Toomey R, O'Reilly C, Brosnan A, et al. Get ireland active! the national physical activity plan for ireland. Dublin: Department of Health, 2016. Available https://www.gov.ie/en/publication/58d193get-ireland-active/

53 Rutter H, Cavill N, Bauman AE, et al. Systems approaches to global and national physical activity plans. Bull World Health Organ 2019;97:162-5.

54 Carson RL, Castelli DM, Beighle A, et al. School-based physical activity promotion: a conceptual framework for research and practice. Child Obes 2014;10:100-6.

55 Bagnall A, Radley D, Jones R, et al. Whole systems approaches to obesity and other complex public health challenges: a systematic review. BMC Public Health 2019;19:8. 